\title{
Ripple Formation by Femtosecond Laser Pulses for Enhanced Absorptance of Stainless Steel
}

\author{
Paulius GEČYS $^{*_{1}}$, Antanas VINČIŪNAS $^{{ }^{* 1}}, \underset{\text { Mindaugas GEDVILAS }}{{ }^{* 1}}$, Albinas KASPARAITIS $^{* 2}$, Rimantas LAZDINAS $^{*_{2}}$ \\ ${ }^{* 1}$ Center for Physical Sciences and Technology, Savanoriu Ave. 231, Vilnius, LT-02300, Lithuania \\ ${ }^{* 2}$ Precizika Metrology, Žirmūnu str. 139, LT-09120, Vilnius, Lithuania \\ E-mail:p.gecys@ftmc.lt
}

\begin{abstract}
Formation of laser induced periodic surface structures (LIPSS), also called ripples, is a widelyknown phenomenon which occurs when multiple laser pulses with the fluence near the material ablation threshold are absorbed by the target material. Ripple formation depends on material properties as well as experimental conditions such as laser wavelength, pulse duration, fluence, number of pulses, polarization etc. Optical properties of the ripple-textured metal surface are changed and this can be employed to blacken the metals to enhance light absorption. In our work, ripples were formed on a stainless steel surface using femtosecond $\mathrm{Yb}: \mathrm{KGW}$ laser (pulse duration $300 \mathrm{fs}$, pulse repetition rate $100 \mathrm{kHz}$ ) operating at $515 \mathrm{~nm}$ wavelength. The ripple period varied between 240 $400 \mathrm{~nm}$ depending on the experimental conditions. Specular reflection measurements at $800 \mathrm{~nm}$ wavelength revealed, that the absortance of the ripple-textured surface increased exponentially with increasing laser irradiation dose (pulse number multiplied by laser fluence). The energy dispersive $\mathrm{X}$-ray chemical analysis (EDS) showed changes in surface chemical composition, therefore both effects contributed to changes in surface absorbtance. The results were applied to control local reflectivity of metallic surfaces.
\end{abstract}

DOI: 10.2961/jlmn.2015.02.0004

Keywords: LIPSS, ripples, femtosecond laser, stainless steel, surface blackening

\section{Introduction}

Laser induced periodic surface structures (LIPSS), also called ripples, have been discovered in 1965 by Birnbaum [1]. From that time, the phenomenon of ripple structure formation was observed on various kinds of solid materials surfaces such as metals [2], semiconductors [3, 4], dielectrics [5], ceramics [6], polymers [7, 8]. The laser-material interaction leading to formation of ripples depend on laser irradiation conditions - wavelength, laser pulse energy and duration, number of pulses applied, polarization direction of the laser field etc. [9] - as well as on material properties: electron-phonon relaxation strength, electronic diffusion, energy band characteristics of the electronic laser excitation [10].

Formation of two distinct types of LIPSS has been observed upon irradiation with multiple linearly polarized femtosecond-laser pulses, called low spatial frequency LIPSS (LSFL) and high spatial frequency LIPSS (HSFL). It is generally considered, that LSFL, having a spatial period close to the irradiation wavelength, are formed due to optical interference of the incident laser radiation with a surface-electromagnetic wave, which is created during the irradiation $[8,11]$. In contrast, the HSFL have spatial periods significantly smaller than the irradiation wavelength and are explained by several proposed mechanisms such as self-organization [12], second harmonic generation [13-15], excitation of surface plasmon polaritons $[11,16]$.

Due to their unique hydrophobic, optical and electronic properties, LIPSS are widely used in emerging fields of nanotechnology such as surface incandescent light sources [17], tribology [18], photoelectron emission [19], photovol- taic cells [20], optical memories [21] and hydrophobicity control of surfaces [22].

Ripples can be also generated on metallic surfaces to enhance their optical properties [23]. Guo et al. reported significant change in optical properties after formation of ripples on aluminium and platinum surface [24]. By adjusting the laser fluence and pulse number, green, golden and black aluminium films were fabricated. Surface absorption enhancement up to $85-95 \%$ was also reported for the blackened Pt and NiTi metals in [23-26]. Laser direct writing of LIPSS enables precise and selective surface structuring which could be applied for manufacturing of various opto-mechanical devices such as linear displacement encoders. In our work we have studied the femtosecond laser induced LIPSS formation on stainless steel in order to enhance its surface absorption.

\section{Experimental}

For the LIPSS generation experiments, the second harmonics of femtosecond $\mathrm{Yb}: \mathrm{KGW}$ laser (Pharos from Light conversion, $515 \mathrm{~nm}$ wavelength, $100 \mathrm{kHz}$ pulse repetition rate) was used with typical pulse duration of $300 \mathrm{fs}$. Linear laser beam polarization was used in all experiments. The laser power was controlled with a half-wave plate and polarizer. The laser beam was focused on the AISI 314 stainless steel sample using a $50 \mathrm{~mm}$ focal length objective. Typical laser spot size on the stainless steel surface was $19 \mu \mathrm{m}$. Translation stages from Aerotech were used for the sample position. The morphology of formed LIPSS was analyzed by an optical (BX51 Olympus), scanning electron (JSM-6490LV JEOL) with EDS spectrometer (Oxford in- 
struments X-Max) and atomic force (Dimension Edge Veeco) microscopes. Specular and diffuse reflection measurements were carried out in a range of 300-1200 nm using integrating sphere method.

\section{Results}

The experiments included formation of ablation crater patterns with different laser fluencies and the number of pulses applied to the same spot in order to investigate the ripple formation phenomenon. The line and area irradiation was also investigated with different laser fluencies and pulse overlap. Areas of $8 \times 8 \mathrm{~mm}^{2}$ were produced for the absorptance measurements.

\subsection{LIPSS formation on stainless steel}

The pattern matrix was formed on the surface using various laser fluence and pulse numbers in order to investigate the ripple formation conditions. Ripple formation dynamics after irradiation with a sequence of laser pulses at the fluence of $0.51 \mathrm{~J} / \mathrm{cm}^{2}$ applied to the surface is shown in the Fig. 1.

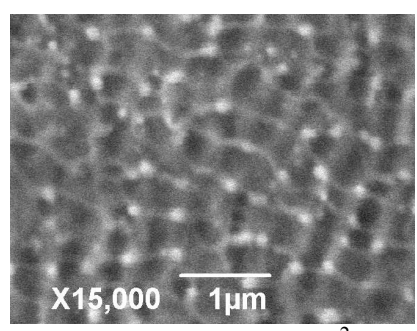

5 pulses, $2.55 \mathrm{~N} \cdot \mathrm{J} / \mathrm{cm}^{2}$

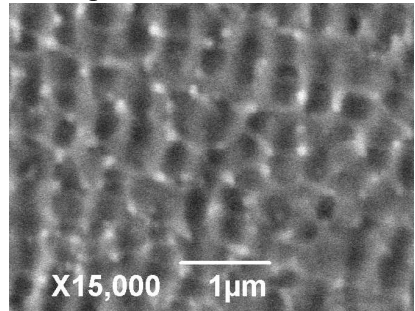

15 pulses, $7.65 \mathrm{~N} \cdot \mathrm{J} / \mathrm{cm}^{2}$

50 pulses, $25.5 \mathrm{~N} \cdot \mathrm{J} / \mathrm{cm}^{2}$

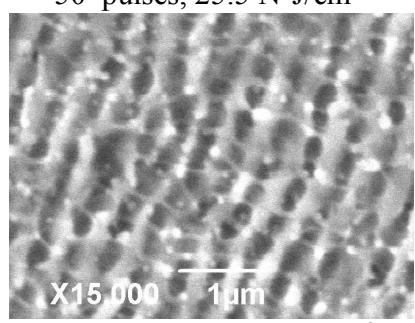

250 pulses, $127.5 \mathrm{~N} \cdot \mathrm{J} / \mathrm{cm}^{2}$

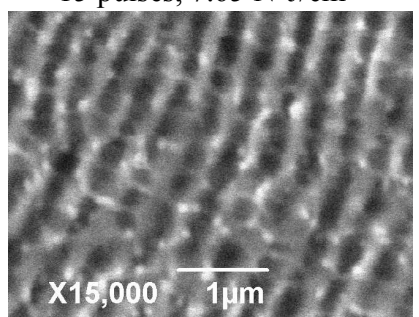

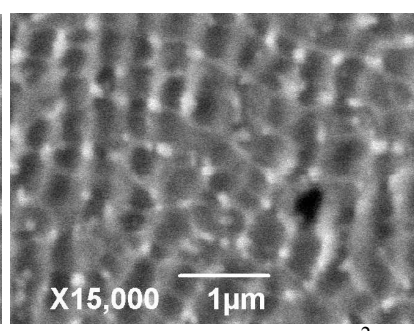

10 pulses, $5.1 \mathrm{~N} \cdot \mathrm{J} / \mathrm{cm}^{2}$

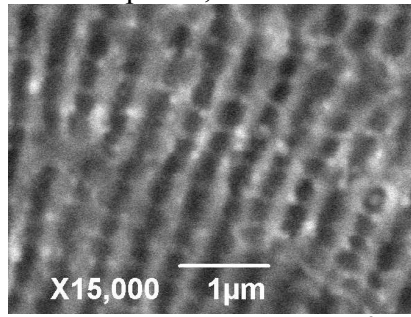

30 pulses, $15.3 \mathrm{~N} \cdot \mathrm{J} / \mathrm{cm}^{2}$

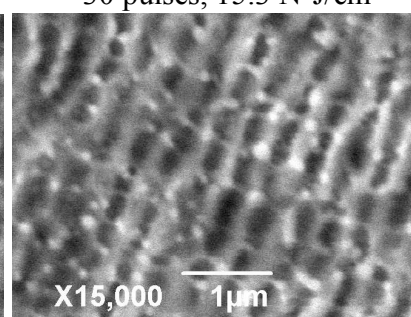

100 pulses, $51 \mathrm{~N} \cdot \mathrm{J} / \mathrm{cm}^{2}$

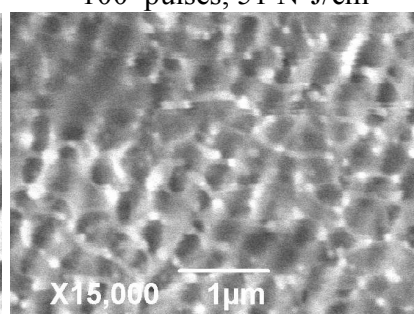

300 pulses, $153 \mathrm{~N} \cdot \mathrm{J} / \mathrm{cm}^{2}$
Fig. 1 Ripple formation dynamics after a sequence of laser pulses was applied to the stainless steel surface. Laser fluence $0.51 \mathrm{~J} / \mathrm{cm}^{2}$, the laser irradiation dose and pulse number applied is showed below each picture.
In investigated process window ripple formation depended on different combinations of laser fluence and pulse overlap, therefore irradiation dose was introduced as a product of these two parameters (fluence $(F)$ multiplied by number of pulses $(N)$ ). Although surface ablation properties are not completely linear with $F$ and $N$ due to fact, that surface modification threshold depends on the number of pulses applied, in our process window the difference in ablation thresholds for different burst of pulses was not significant. When 5 laser pulses were absorbed by the target, structural changes in stainless steel surfaces with irregular roughness close to $500 \mathrm{~nm}$ period, as well as nanoparticles with diameter of $\sim 100 \mathrm{~nm}$ were observed. This regime corresponded to laser irradiation dose of $2.55 \mathrm{~N} \cdot \mathrm{J} / \mathrm{cm}^{2}$. Increase of laser irradiation dose up to $5.1-7.65 \mathrm{~N} \cdot \mathrm{J} / \mathrm{cm}^{2}$ (pulse number up to $10-15$ per spot) resulted in periodic ordering of the surface. Regular periodic ripples were formed when laser irradiation dose was in the range of $15.3-51 \mathrm{~N} \cdot \mathrm{J} / \mathrm{cm}^{2}$ (30-100 pulse number per spot), but they tend to disappear when laser irradiation dose was increased up to $127.5-153 \mathrm{~N} \cdot \mathrm{J} / \mathrm{cm}^{2}$ (250-300 pulse number per spot). At this overdose regime, strict periodic structure started to disappear. Formation of nanodroplets with size of several hundred nanometers indicated melting of the laser irradiated surface.

Relationship between the ripple period and laser fluence applied to the sample was also observed (see Fig. 2).

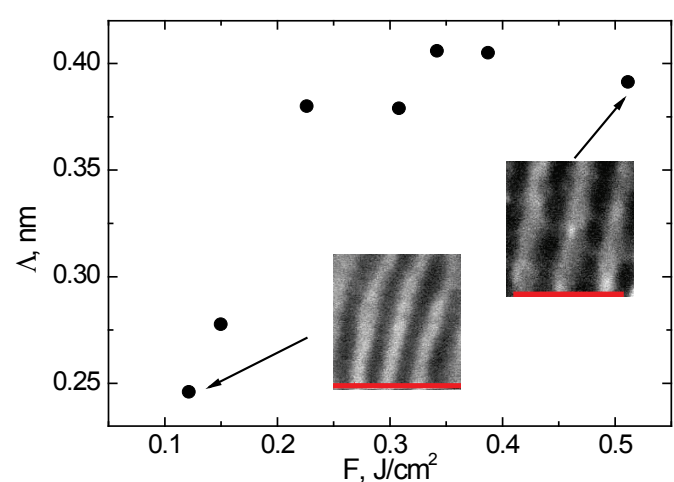

Fig. 2 Relationship between the laser fluence and ripple period on stainless steel surface, 50 pulses per spot.

The ripple period tend to grow while the laser fluence was increased. This is in good agreement with other studies presented in [27, 28]. In all cases, the ripple period was between 240 and $400 \mathrm{~nm}$ and was smaller than the laser wavelength of $515 \mathrm{~nm}$.

\subsection{Reflection of surfaces textured by ripples}

In order to evaluate reflection of a surface textured by ripples, stainless steel areas of $8 \times 8 \mathrm{~mm}^{2}$ were modified by the laser using different laser fluencies and pulse overlap. Laser structured areas were examined with an optical microscope and 5 processing regimes were selected for the specular and diffuse reflection measurements. Only surface modification was observed in these selected areas without significant material ablation. The laser fluence, pulses per spot and irradiation doze parameters are shown in Table 1. Optical microscope images of the laser modified regions are shown in Fig. 3. 
Table 1 Parameters of the laser structured areas.

\begin{tabular}{cccc}
\hline No. & $\begin{array}{c}\text { Fluence } \\
F_{0}, \mathrm{~J} / \mathrm{cm}^{2}\end{array}$ & $\begin{array}{c}\text { Pulses } \\
\text { per spot }\end{array}$ & $\begin{array}{c}\text { Irradiation dose } \\
F_{0} \cdot N, \mathrm{~J} / \mathrm{cm}^{2}\end{array}$ \\
\hline 1 & 0.35 & 19 & 6.65 \\
2 & 0.21 & 56 & 11.76 \\
3 & 0.18 & 93 & 16.74 \\
4 & 0.11 & 112 & 12.32 \\
5 & 0.079 & 374 & 29.5 \\
\hline
\end{tabular}

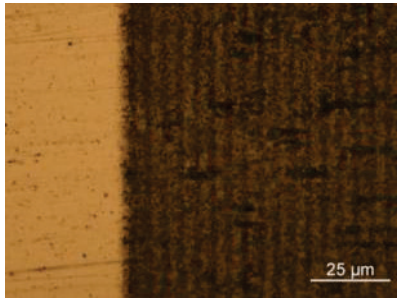

(a)

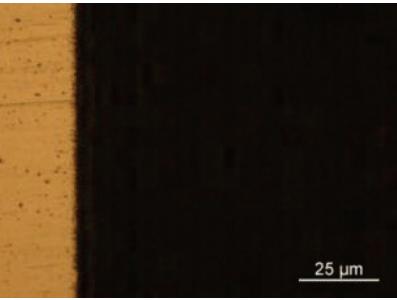

(b)
Fig. 3 Optical microscope image of laser structured areas: (a) No. $10.35 \mathrm{~J} / \mathrm{cm}^{2}, 19$ pulses per spot, $6.65 \mathrm{~N} \cdot \mathrm{J} / \mathrm{cm}^{2}$; (b) No. 5 $0.08 \mathrm{~J} / \mathrm{cm}^{2}, 374$ pulses per spot, $29.5 \mathrm{~N} \cdot \mathrm{J} / \mathrm{cm}^{2}$.
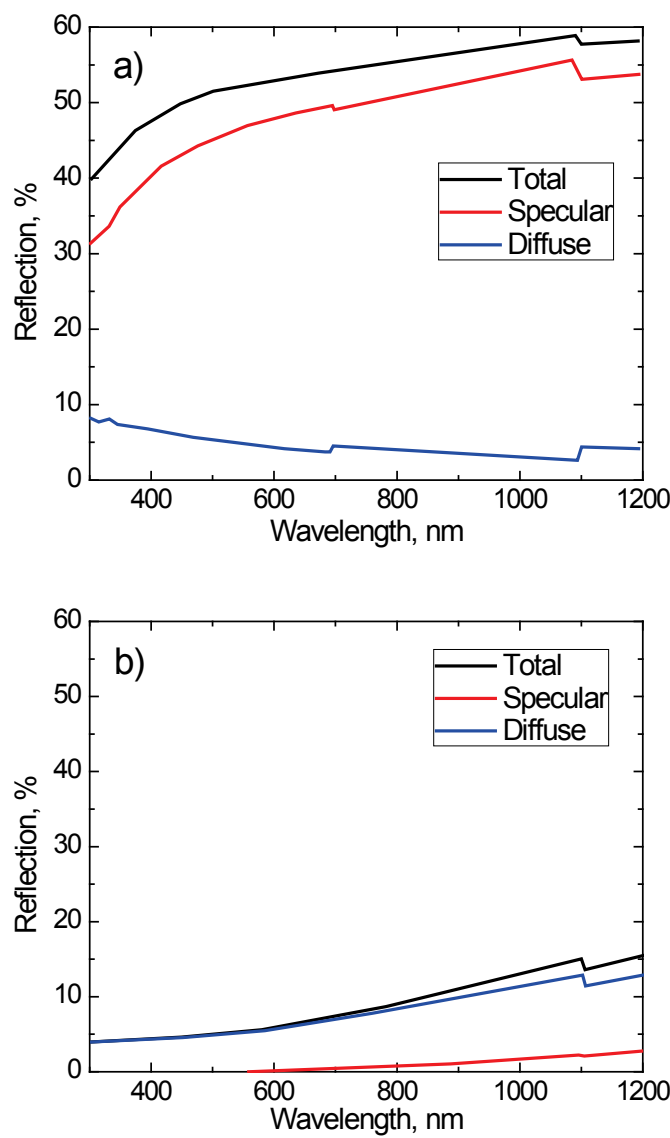

Fig. 4 Reflection measurements of ripple structured area: (a) laser unaffected surface; (b) after laser irradiation. Fluence $0.08 \mathrm{~J} / \mathrm{cm}^{2}$, 374 pulses per spot, $29.5 \mathrm{~N} \cdot \mathrm{J} / \mathrm{cm}^{2}$.
Reflection spectra of untreated and ripple-textured (regime No. 5) surfaces are shown in Fig. 4. It is clearly noticeable, that optical properties of surface were modified after surface irradiation - the total reflection was significantly reduced in all spectral range due to significant decrease in specular reflection. Total reflection of rippletextured surface was mainly determined by diffuse reflection while specular reflection was close to zero, because ripples acted as light scattering surface. No noticeable relationship between the laser irradiation dose and diffuse reflection were observed for all ripple structured areas.

The diffuse reflection varied less than $8 \%$ in all laser modified regions. Therefore, only specular reflections were examined in further analysis. Most opto-mechanical devices such as linear displacement encoders operate at infrared spectrum range (close to $800 \mathrm{~nm}$ wavelength), therefore this spectral range was selected for further investigations.

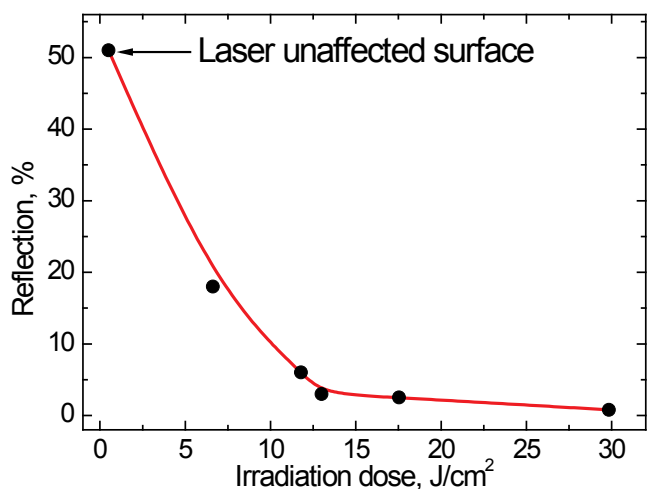

Fig. 5 Relationship between the specular reflection at $800 \mathrm{~nm}$ wavelength and laser irradiation dose.

Relationship between the specular reflection at $800 \mathrm{~nm}$ wavelength and the laser irradiation dose is shown in Fig. 5. The specular reflection dropped exponentially with increasing irradiation dose, absorbed by stainless steel surface. Steep surface reflectivity drop from 18 to $3 \%$ was observed when the laser irradiation dose was increased from $6.65 \mathrm{~N} \cdot \mathrm{J} / \mathrm{cm}^{2}$ up to $12.32 \mathrm{~N} \cdot \mathrm{J} / \mathrm{cm}^{2}$, respectively. When the laser irradiation dose was increased above $16.74 \mathrm{~N} \cdot \mathrm{J} / \mathrm{cm}^{2}$, further surface reflectivity decrease was insignificant. Overall specular reflection of the laser textured stainless steel surface at $800 \mathrm{~nm}$ wavelength was reduced from 51 to $1 \%$ compared to laser unaffected surface.

\subsection{Ripple textured surface chemical analysis}

Changes in chemical composition of laser treated metal surface is well known phenomenon [29-32]. Therefore, EDS analysis was also applied to investigate changes of the relative element content in laser irradiated areas of the sample surface. Chemical compositions of laser treaded surfaces are shown in the Table 2.

The EDS analysis of laser processed surface revealed clear relationship between the surface concentrations of oxygen and carbon and the laser irradiation dose. Changes of silicon content was also observed, although it was insignificant compared to oxygen or carbon. 
Table 2 Chemical compositions of laser treated AISI 314 stainless steel surfaces.

\begin{tabular}{|c|c|c|c|c|c|c|}
\hline & & \multicolumn{5}{|c|}{ Weight, \% } \\
\hline \multirow{7}{*}{$\begin{array}{l}\dot{0} \\
z \\
\mathscr{z} \\
\stackrel{0}{0} \\
\stackrel{0}{0}\end{array}$} & Element & $\mathrm{C}$ & $\mathrm{O}$ & $\mathrm{Si}$ & $\mathrm{Cr}$ & $\mathrm{Fe}$ \\
\hline & Unaffected & 1.77 & - & 0.27 & 17.5 & 80.46 \\
\hline & 1 & 4.54 & 2.63 & 0.32 & 15.55 & 76.97 \\
\hline & 2 & 4.43 & 3.01 & 0.41 & 15.42 & 76.74 \\
\hline & 3 & 5.21 & 4 & 0.39 & 15.41 & 74.99 \\
\hline & 4 & 5.31 & 3.91 & 0.39 & 15.74 & 74.64 \\
\hline & 5 & 6.63 & 6.4 & 0.45 & 15.76 & 70.76 \\
\hline
\end{tabular}

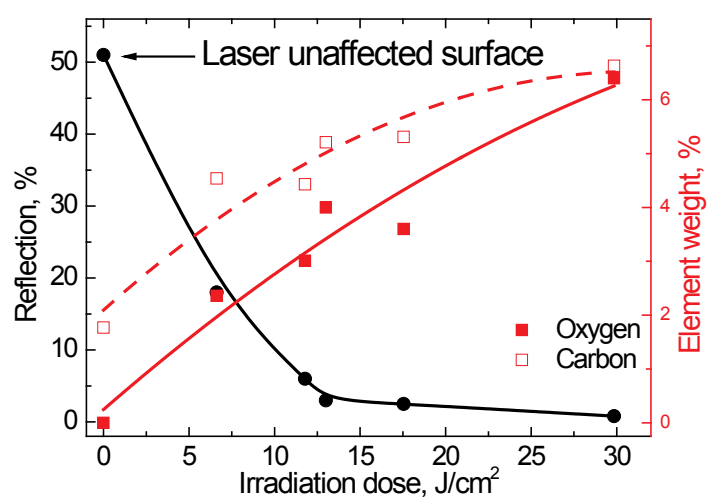

Fig. 6 Relationship between the specular reflection at $800 \mathrm{~nm}$ wavelength, surface chemical composition and laser irradiation dose.

At the laser unaffected surface the content of oxygen and carbon were 0 and $1.77 \%$ respectively (see Fig. 6). With increasing laser irradiation dose the oxygen and carbon levels started to increase reaching up to 6.4 and $6.63 \%$ respectively at laser irradiation dose of $29.5 \mathrm{~N} \cdot \mathrm{J} / \mathrm{cm}^{2}$. The relationship between the surface chemical composition and specular reflection was obvious.

\subsection{Ripple textured surface morphology}

In order to investigate surface properties of laser treaded surfaces, atomic force microscopy (AFM) was applied. Surface morphology and ripple depth profiles were investigated in the laser textured areas with different processing conditions. Typical rippled surface of the laser modified area is shown in Fig. 7. Periodic structure with regular parallel oscillations in the range of $240 \mathrm{~nm}$ is observed in the AFM image. The small-scale roughness of tens of nanometers is also observed covering the ripple top and grooves.

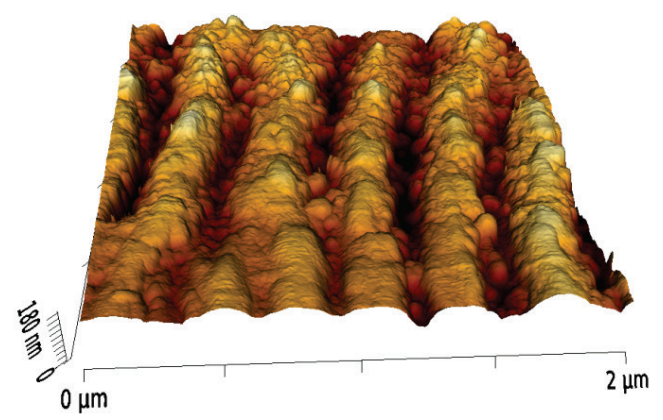

Fig. 7 AFM image of ripple structured area. Fluence $0.08 \mathrm{~J} / \mathrm{cm}^{2}$, 374 pulses per spot, $29.5 \mathrm{~N} \cdot \mathrm{J} / \mathrm{cm}^{2}$.
It was determined, that ripple depth varied in range of 130 to $220 \mathrm{~nm}$ and showed logarithmic dependence on the laser irradiation dose applied to the surface (see Fig. 8).

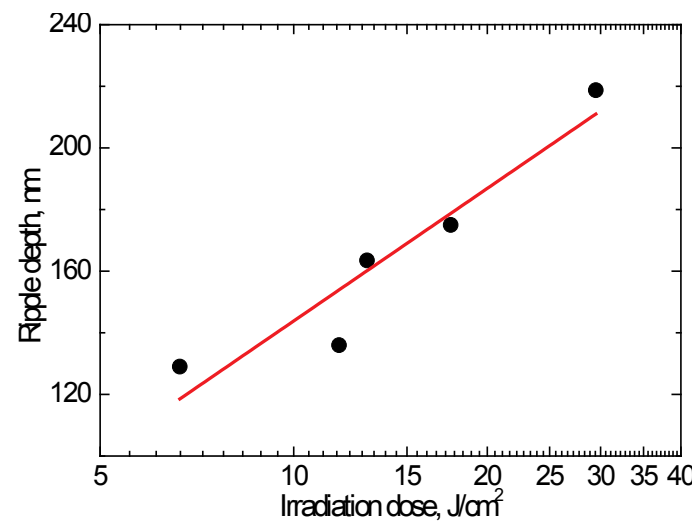

Fig. 8 Relationship between the laser irradiation dose and ripple depth.

Ripples tend to grow while the laser irradiation dose was increased. This is predictable result, since after formation of initial shallow ripples, the energy of following laser pulses is concentrated in the ripple grooves [23, 33], and ablation effectively takes place in ripples grooves and they become deeper. The relationship between the surface specular reflection and ripple groove depth was also observed. Deeper ripples could increase the light trapping effect, therefore it could also affect the specular surface reflection (see Fig. 9).

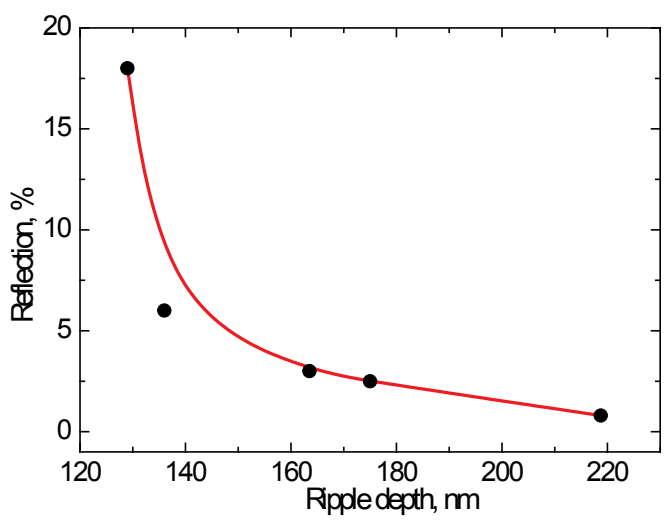

Fig. 9 Relationship between the specular surface reflection and ripple depth.

\section{Conclusions}

Regular periodic ripples were formed when laser irradiation dose was in the range of $15.3-51 \mathrm{~N} \cdot \mathrm{J} / \mathrm{cm}^{2}$, but they tend to disappear when laser irradiation dose was increased above $127.5 \mathrm{~N} \cdot \mathrm{J} / \mathrm{cm}^{2}$. Growth of the ripple period from 240 to $400 \mathrm{~nm}$ was observed with increasing laser fluence, although in all cases it was smaller than the laser wavelength. Chemical surface composition changes were observed in the laser textured areas. Increase of oxygen and carbon concentrations were detected with increasing the laser irradiation dose. Surface reflection investigations revealed exponential reflectivity dependence on the laser irradiation dose. Furthermore, the specular reflection of stainless steel at $800 \mathrm{~nm}$ wavelength was reduced from 51 to $1 \%$. This behaviour was related to changes in surface chemical com- 
position and the growth in the ripple depth with increasing effect of light trapping, therefore both the surface chemical and morphological changes contributed to enhancement of surface absorbtance.

\section{References}

[1] M. Birnbaum: J. Appl. Phys., 36, (1965) 3688-3689.

[2] A. Y. Vorobyev and C. Guo: Appl. Phys. A, 86, (2007) 321-324.

[3] M. Shen, J. E. Carey, C. H. Crouch, M. Kandyla, H. A. Stone and E. Mazur: Nano Lett., 8, (2008) 2087-2091.

[4] B. Kumar and R. K. Soni: J. Phys. D: Appl. Phys., 41, (2008) 155303.

[5] E. Simova, C. Hnatovsky, R. S. Taylor, D. M. Rayner and P. B. Corkum: Proc. Photon Processing in Microelectronics and Photonics VI, San Jose, CA, (2007) p.64581B.

[6] J. Bonse, H. Sturm, D. Schmidt and W. Kautek: Appl. Phys. A, 71, (2000) 657-665.

[7] S. Baudach, J. Bonse and W. Kautek: Appl. Phys. A, 69, (1999) S395-S398.

[8] J. Sipe, J. Young, J. Preston and H. van Driel: Phys. Rev. B, 27, (1983) 1141-1154.

[9] S. K. Das, H. Messaoudi, A. Debroy, E. McGlynn and R. Grunwald: Opt. Mater. Express, 3, (2013) 17051715.

[10]J. P. Colombier, F. Garrelie, N. Faure, S. Reynaud, M. Bounhalli, E. Audouard, R. Stoian and F. Pigeon: J. Appl. Phys., 111, (2012) 024902.

[11]R. Le Harzic, F. Stracke and H. Zimmermann: J. Appl. Phys., 113, (2013) 183503.

[12]F. Costache, M. Henyk and J. Reif: Appl. Surf. Sci., 208-209, (2003) 486-491.

[13]X. C. Zhang, B. B. Hu, J. T. Darrow and D. H. Auston: Appl. Phys. Lett., 56, (1990) 1011-1013.

[14]T. Q. Jia, H. X. Chen, M. Huang, F. L. Zhao, J. R. Qiu, R. X. Li, Z. Z. Xu, X. K. He, J. Zhang and H. Kuroda: Phys. Rev. B, 72, (2005) 125429.

[15]R. Le Harzic, D. Dörr, D. Sauer, F. Stracke and H. Zimmermann: Appl. Phys. Lett., 98, (2011) 211905.

[16]G. Miyaji and K. Miyazaki: Opt. Express, 16, (2008) 16265-16271.

[17]A. Y. Vorobyev, V. S. Makin and C. Guo: Phys. Rev. Lett., 102, (2009) 234301.

[18]J. Eichstädt, G. R. B. E. Römer and A. J. H. i. t. Veld: Phys. Procedia, 12, Part B, (2011) 7-15.

[19]T. Y. Hwang, A. Y. Vorobyev and C. Guo: Phys. Rev. B, 79, (2009) 085425 .

[20]R. Torres, T. E. Itina, V. Vervisch, M. Halbwax, T. Derrien, T. Sarnet, M. Sentis, J. Ferreira, F. Torregrosa and L. Roux: AIP Conf. Proc., 1278, (2010) 576-581.

[21]Y. Shimotsuma, M. Sakakura, K. Miura, J. Qiu, P. G. Kazansky, K. Fujita and A. Hirao: J. Nanosci. Nanotechnol., 7, (2007) 94-104.

[22]T. Baldacchini, J. E. Carey, M. Zhou and E. Mazur: Langmuir, 22, (2006) 4917-4919.

[23]S. Hou, Y. Huo, P. Xiong, Y. Zhang, S. Zhang, T. Jia, Z. Sun, J. Qiu and Z. Xu: J. Phys. D: Appl. Phys., 44, (2011) 505401.

[24]A. Y. Vorobyev and C. Guo: Appl. Phys. Lett., 92, (2008) 041914.
[25]B. Dusser, Z. Sagan, H. Soder, N. Faure, J. P. Colombier, M. Jourlin and E. Audouard: Opt. Express, 18, (2010) 2913-2924.

[26]Y. Yang, J. Yang, C. Liang and H. Wang: Opt. Express, 16, (2008) 11259-11265.

[27]S. Sakabe, M. Hashida, S. Tokita, S. Namba and K. Okamuro: Phys. Rev. B, 79, (2009) 033409.

[28]K. Okamuro, M. Hashida, Y. Miyasaka, Y. Ikuta, S. Tokita and S. Sakabe: Phys. Rev. B, 82, (2010) 165417.

[29]A. J. Antończak, Ł. Skowroński, M. Trzcinski, V. V. Kinzhybalo, Ł. K. Łazarek and K. M. Abramski: Appl. Surf. Sci., 325, (2015) 217-226.

[30]C. Y. Cui, X. G. Cui, X. D. Ren, M. J. Qi, J. D. Hu and Y. M. Wang: Appl. Surf. Sci., 305, (2014) 817-824.

[31]L. Kotsedi, Z. Y. Nuru, P. Mthunzi, T. F. G. Muller, S. M. Eaton, B. Julies, E. Manikandan, R. Ramponi and M. Maaza: Appl. Surf. Sci., 321, (2014) 560-565.

[32]C. Y. Cui, X. G. Cui, Q. Zhao, J. D. Hu, Y. H. Liu and Y. M. Wang: Opt. Laser Technol., 44, (2012) 815-820.

[33]J. W. Yao, C. Y. Zhang, H. Y. Liu, Q. F. Dai and L. J. Wu: Opt. Express, 20, (2012) 905-911.

(Received: July 2, 2014, Accepted: January 28, 2015) 